\title{
The Re-designing of Business Education through Web Tools: From Universities Web-radio to On-line Magazines
}

\author{
Maddalena della Volpe ${ }^{1}$, Francesca Esposito ${ }^{2}$ \\ ${ }^{1}$ Associate Professor in Economy and Business Management, Department of Business, Management and \\ Innovation System, University of Salerno, Italy \\ ${ }^{2}$ PHD in Business and Communication, Department of Political, Social and Communication Sciences, University \\ of Salerno, Italy \\ Correspondence: Maddalena della Volpe, Associate Professor in Economy and Business Management, \\ Department of Business, Management and Innovation System, University of Salerno, Italy.
}

Received: July 26, 2017

doi:10.5539/ibr.v10n10p94
Accepted: September 7, $2017 \quad$ Online Published: September 21, 2017

URL: https://doi.org/10.5539/ibr.v10n10p94

\begin{abstract}
Traditional teaching methods should be redesigned and renewed by consulting all those involved in the learning process: students, teachers, institutions, companies, in order to create a network whose aim is to exchange and transfer knowledge. The criteria used to choose a distance learning course program, should also be applied to building the right network to reach pre-determined goals. In both cases, we have a classroom- real or virtual- and it is only when we step outside the usual learning environment, that we can increase learning opportunities, by stimulating and motivating learners in a new way. Stepping out from a traditional classroom environment re sults in an open mind regarding the world of work, especially in the field of Business Education. New ,innovative and creative web 2.0 tools, such as university web-radios and on-line magazines could offer this opportunity by modifying teaching methods as could being part of the above-mentioned network . Moreover, both tools are user-friendly, cheap and quite simple to put into practice and manage. As there was little data available regarding Italian uni versity web-radios and national academic magazines, we decided to carry out our own research. Little research had been previously carried out in this area.

In this paper, we refer to WayOut a pilot project aimed at developing an entrepreneurial mindset by, engaging students in an interesting learning environment in order to make them capable of managing their life project, of reaching specific goals and subsequently of being able to take advantage of opportunities, which arise. Our aim is to encourage interaction between universities and businesses by removing the barriers between the internal and the external environment, thus making reciprocal knowledge transfer easier: from the company to the university and from university to the company.
\end{abstract}

Keywords: business education, university business cooperation, on-line magazine, university web-radio, Web 2.0

\section{Introduction}

Web 2.0 technologies facilitate learning, improve communication, share knowledge, and allow users to collaborate with each other: they also offer teachers a wide range of opportunities to help enhance students' education. We believe that they can be used in higher education to develop an entrepreneurial mindset in students. That is, the ability necessary to manage their life project, to reach specific goals and subsequently be able to take full advantage of opportunities, which arise. They are often useful tools for Learning Management Systems (Bower, 2016) because they can be applied to promote new ways of learning. The Web 2.0 concept began when O'Reilly (2007), who first used the term at a conference, argued that it is a platform with friendly interfaces: it enables users to offer their own contribution by participating, by sharing information, by being engaged in publishing, by linking, tagging and commenting. Nowadays there is no common definition regarding the meaning of web 2.0, as it refers to two key elements: a platform where users participate in controlling, sorting and creating data or content. Digital convergence allows an omni-directional flow of communication where every user is, at the same time, information producer and user: everyone can use content created by other users and can also create new content, sharing it with his or her community (della Volpe, 2013 p.5). Thanks to this strong user interaction, a perpetual beta is triggered; that is a continuous update and upgrade process, in direct 
relation to prompt feedback from users. Tools, such as blogs, social networks, magazines, offer low technological barriers so that everyone can create and publish freeform contents. Companies pay great attention to web 2.0 tools as they stimulate collaboration, innovation, creativity and knowledge sharing resulting in a competitive advantage. They are cheap, attractive, and very useful for advertising campaigns, for communicating and for building or strengthening their corporate reputation without onerous investment. These tools are most commonly employed in the fields of Marketing, Communication and E-Commerce. We believe universities should make similar use of them, in order to engage students and teachers in a new relationship, where learning is a shared goal, which can be achieved, through online participation by users who contribute and shape new content.

In the second paragraph, we discuss already published papers in favour of web 2.0 tools as a teaching aide in higher education. We focus particularly on university web-radios and on-line magazines within the University Business Cooperation (UBC). In the third paragraph, we examine international data about the tools considered and we discuss our findings related to web-radios and on-line magazines in Italian universities. The fourth paragraph is dedicated to a pilot project, called WayOut, where we put these tools into practice to enhance an entrepreneurial mindset in students. Finally, we observe how traditional teaching activities could be redesigned by creative and innovative tools.

\section{Literature Framework}

In this paragraph, we look at published papers regarding web 2.0 tools in higher education particularly papers which explore the relationship between uni versities and their partners, involved in building a network to achieve the third mission. We refer to Entrepreneurial University (EU) literature, which looks at how UBC .Web 2.0 tools could facilitate dialogue between students and teachers, by developing new inquiries, prompting social feedback and building. a learning network (Boyd, 2007). In other words, they are a great opportunity for higher education. However, it is not enough only to add social networks to a university website: in this way, web 2.0 technologies are undervalued. Universities need to discover and develop their potential regarding teaching, learning and communication.

Let us use blogs, as an example, Bower (2016) specifies that they are a chronological posting of information on the Web, which could be used to create an e-portfolio for a course (p.773). Generally, higher education places more importance on tools based on collaborative experience, such as blogs, forum, wiki, etc., while tools based on an exchange of information are not recognised as having a strong impact on learning. So, by developing new simple, useful applications we can redesign education both in its traditional learning environment (classroom) as well as in its virtual one (web platform).

Within an educational context, web 2.0 tools provide new paths to implement the learning experience, where the student is a user who cooperates in defining the content. That is why it is important to integrate them in traditional and formal learning activities such as in an e-learning environment to improve results and to take advantage of new technologies. Learning by means of web 2.0 tools is focused on the personalization of experience and on engagement. Web 2.0 tools have great potential, even if it there is some institutional resistance to change, improvisation and unplanned learning (Jenkins, 2006; Downes, 2005; De Pablos 2007; Conde et al., 2014). Universities can exploit web 2.0 tools in accordance with their renewed three missions, which require the rethinking of strategies in order to reach their goals in the competitive, contemporary education market.

A survey carried out by Bennett et al. (2012) proved that implementing web 2.0 tools was positive for the development of student skills as well as, improving key values such as collaboration and user generated content, while blog creation was an indicator of knowledge sharing capability. Levine and Sun (2002) point out that the internet shapes three different forms of universities: brick, click and brick-click. The first one is based on campus, the second one includes on-line learning, distance learning, i.e. a mobile university, the third one is a mixed form (Kulakli and Mahony, 2014): from a university perspective and strategy, it shows the visibility of social media tools on uni versity home pages. Howe ver, we can observe worldwide that universities do not consider the use of social media important here -use of media like ITunes, RSS, Flickr, blog, LinkedIn, Foursquare, Google+, Stumbleupon, iPhone App (in decreasing order) is low- while Twitter, Facebook and YouTube are the most popular in the top 50 universities in the world. This means, in our opinion, that there is still considerable research to be carried out in the use of social media in education. We feel this lack of research results in beneficial educational advantages being lost (see Table 1). Howe ver, an increasing interest regarding the implementation of these tools does help university communication. 
Table 1 . The visibility of social media tools in university home page

\begin{tabular}{|c|c|c|c|c|c|c|c|c|c|c|c|c|}
\hline Institutions Rank & $\begin{array}{l}y \\
\\
8 \\
8 \\
0 \\
0 \\
\end{array}$ & 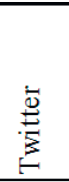 & $\frac{\infty}{\infty}$ & $\begin{array}{l}\tilde{A} \\
\tilde{x}\end{array}$ & 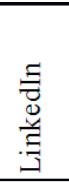 & $\stackrel{\mathscr{E}}{\Xi}$ & 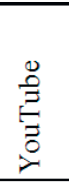 & 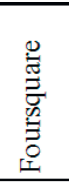 & $\begin{array}{l}+ \\
\frac{0}{00} \\
0 \\
8 \\
8\end{array}$ & 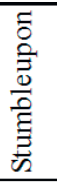 & 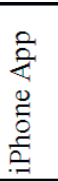 & $\frac{\vec{t}}{\frac{\vec{\theta}}{I}}$ \\
\hline \multirow[t]{2}{*}{ Top 50 World } & 41 & 42 & 4 & 15 & 3 & 16 & 30 & 6 & 3 & 1 & 1 & 7 \\
\hline & $82 \%$ & $84 \%$ & $8 \%$ & $30 \%$ & $6 \%$ & $32 \%$ & $60 \%$ & $12 \%$ & $6 \%$ & $2 \%$ & $2 \%$ & $14 \%$ \\
\hline \multirow[t]{2}{*}{ Top $50 \mathrm{UK}$} & 40 & 41 & 2 & 12 & 7 & 8 & 33 & 3 & 3 & 2 & 1 & 13 \\
\hline & $80 \%$ & $82 \%$ & $4 \%$ & $24 \%$ & $14 \%$ & $16 \%$ & $66 \%$ & $6 \%$ & $6 \%$ & $4 \%$ & $2 \%$ & $26 \%$ \\
\hline
\end{tabular}

Source: Kulakli and Mahony (2014), page 652.

Tapscott and Williams (2010) highlight the collaborative aspect of the knowledge production process, which requires significant change in the current university structure. Their theory is based on an open approach. They designed the Global Network for Higher Learning, a model in five steps for creating and sharing knowledge in teaching and in learning at university. They also point out the benefits of web 2.0 tools: students' motivation and learning, a softening of learning borders, more interdisciplinary support, the development of multitasking skills, for example.

Referring to EU published papers, we considered, first of all, the most famous author in this field and relative successive developments. According to Etzkowitz (1983; 2002), the Triple Helix is based on uni versity-industry-government relationships which represent a spiral model of cooperation, where every subject plays a central role within a common network in order to enhance innovation in a knowledge-based society and by contributing in this way obtains the greatest possible benefit from the relationship. This concept evolves into the Quadruple Helix model where Carayannis and Campbell (2009) added a helix, which has been defined more 'public. 'Public', includes the "media-based and culture-based public" as well as "civil society". It is associated with new aspects such as media, creative industries, values, lifestyle, art, creativity, culture and particularly innovation culture. In this advanced system, communities play a central role: by applying knowledge, they become an innovation engine. This concept underlines a new aspect of knowledge environment: creativity.

Finally, the Quintuple Helix model introduces a fifth helix: the natural environment. It is considered "as a framework for trans-disciplinary (and interdisciplinary) analysis of sustainable development and social ecology" (Carayannis \&Campbell, 2010 p.62). The traditional role of university research, based on a linear innovation model, has been replaced by interdisciplinary research. Subsequent different ways of innovation and knowledge have evolved together, (being growth factors for societies and economies), by paying attention to new values: creativity, environment, and sustainability. The path is aimed at a system of cooperation and knowledge, which involves natural and social sciences as well as the humanities. The natural environment, society and democracy are pillars for the economy and its sustainable development. (Carayannis et al. 2012). Wissema (2009) traces the historic development of universities and at the same time, explores technology-based companies, start-up techno-starters and financiers as partners of the Third Generation University. The author points out the new role of the university as an incubator of new science and technology-based enterprises, as well as being an active player in the know-how exploitation: a third university aim. In entrepreneurial education, universities play a central role, too. Narayanan (2010) highlights the importance of internships within the UBC. They are a bridge leading to the world of work and "a two-way knowledge transfer" process. In fact, a company produces knowledge just like a university and a student, during his/her internship, transfers new and inno vative kno wledge to organizations. Then, when the student goes back to university, he can transfer his/her enriched knowledge to his/her university.

It was at the University of Cincinnati in 1906 when the concept of university being a mix of class hours and work experience was born. Herman Schneider (1872-1939), creator of the educational project, designed the program. Cooperative education (often shortened to $c o-o p$ ), based on the integration of internships within an academic educational course. This program has since been expanded widely in the US and Canada. Khan (2012) and Roper (2013), talking about future uni versities and of an educational system to be re-imagined, are referring to a university model founded on cooperative education, practical experience and internships, such as are on offer at Waterloo University in Canada, one of the most highly considered universities in the world for engineering. This university offers 24 months of curricular internships to their students. In a scenario characterized by a high level of technological innovation, learning by doing could represent a new frontier for universities. 
From our consultation of published research, we have ascertained that dialogue and communication between teacher and student can change and enhance the learning process. . Let us now consider if web 2.0 tools could be useful in the same way, by changing the parties involved, by looking at dialogue and cooperation between university and the business world. New, innovative and creative web 2.0 tools, such as university web-radios and on-line magazines could offer this opportunity, by modifying the way of teaching and by becoming an integral part of the network already mentioned. They encourage the development of relationships through a new way of interaction giving students the opportunity to share ideas and to compare themselves to others. In some cases, they can start projects or activities with unexpected partners or even embark on a start-up or spin-off project. Moreover, both tools are user-friendly and engage students while being cheap, quite simple to manage and put into practice.

\section{Web-radi os and On Line Magazines through Data}

Radio is music: a talk show or an interview is only an interruption in the music flow. Web-radio is based on radio broadcast on the Internet and being on-line eradicates any geographical limits, so the amount of material a listener can be exposed to is potentially very high. That is the most important difference between traditional radio and web radio.

Recently the average age of young people who listen to the radio has increased from 14 to 24 years old and they listen on average to 182 minutes a day, thanks to the numerous devices they can use: smartphones, tablet as well as PCs (GfK Eurisko \& Ipsos, 2015). Web-radio consumer listening grew all over the world thanks to streaming, which personalizes, what is available and offers on demand access. Radio has followed technological innovation better than any other medium: it is second only, to television and has a high audience share: $84 \%$. Radio websites and streaming make easy listening. This rising, web radio audience share is prevalent in many countries. For example, in the US there were 176.5 million web-radio listeners in 2016 , an increase of $+29.2 \%$ from 2013 . Famous streaming radios such as Pandora or Spotify have contributed to this growth. A similar increase has also been seen in the UK. Live radio is listened to by $90 \%$ of the British population. Young people, from 15-24 years of age, spend more time streaming than downloading (della Volpe \& Esposito, 2017).

As there was very little national data regarding the presence and use of web radio in Italian universities, in 2016 we carried out a census: only $48 \%$ of universities had a web-radio and only a minority considered the entrepreneurial and innovative aspect of web radio in their programs. As for geographical area, we found that $43 \%$ of universities in Northern Italy had a web radio. This was in keeping with the higher social, economic and innovative development in this area. We only looked at official, institutional web-radios, managed by the university boards and excluded independent web radios, created and managed by students. We analysed the content of the broadcasting schedule and we observed that there is an increase in the number of planned programs planned regarding innovation and entrepreneurship. .In this way, the relationship between University, Industry, Institutions and Citizens is encouraged and strengthened.

At this point, we considered the other tool we were focusing on: on-line magazines. An on-line magazine is defined as a magazine, which is published on the Internet. Historically, on-line magazines are the forerunners of print magazines, sometimes called "webzines". The term "ezine" or "e-zine" is a specialised word, which refers to small magazines or newsletters distributed by e-mail or other electronic modes. On-line magazines have a lot in common with blogs and on-line newspapers: their distinguishing feature is related to their approach regarding editorial control. Generally, magazines have editors or editorial boards to assure quality, publishers' expectations and readers. On-line magazines represent an interesting and unexplored field for academics, scientists and industries.

A lack of data regarding on-line magazines could be interpreted as a lack of scientific interest in this tool. Data was also lacking regarding university on line magazines, so we created a data bank of national academic on-line magazines We looked at name, university, language, authors, editorial staff, national or international in scope, purpose, contents, upgrading level, web usability, advertising space, target, social media, link to apps or other, websites. We identified average web usability by using the six most commonly used requirements; that are website navigability, waiting time, completeness of contents, comprehensibility of information, effective communication, graphic attractiveness. Web usability directly influences accessibility. According to Tim Berners-Lee (1997), "The power of the Web is in its universality. Access by everyone regardless of disability is an essential aspect".

The aim of the data set aim was to compare university on-line magazines and find out if, in some part, they looked at fostering an entrepreneurial mindset through their content .An entrepreneurial mindset can be developed through both knowledge and information provided by the web 2.0 tools described, but also by being 
directly involved in activities related to their realisation. A student could participate as an author or be involved at an organizational level, as an interviewer or as an editor, under the direction of a teacher or experts, for example. This would be real work experience for students: it could be in the form of an internship within the university.

In our survey, we observed that there are 97 Universities in Italy (www.cineca.it) and yet, we found only 29 had an institutional on-line magazine. Regarding their geographical position we found 13 on-line magazines (44.8\%) in universities in Northern Italy, 7 (24.1\%) in the Centre and 9 (31.1\%) in South.

We found that all 29 magazines used Italian, only 6 (20.7\%) added an English version, and only 2 (6.9\%) of them added a Chinese one, while just 1(3.4\%) had a French and a German version, too. The authors were not named in 14 cases $(48.3 \%)$, while they were described as experts in 15 cases $(51.7 \%)$ and students in $2(6.9 \%)$. The topics dealt with are national and international in 12 cases (41.4\%), while exclusively national topics prevail in 17 cases $(58.6 \%)$. For all magazines, the main purpose is information.

Regarding the contents section, we noted that $19(65.5 \%)$ of university magazines have an Events section, followed by Innovation and Research, devoted to the dissemination of purely scientific news in 17 (58.6\%) magazines. Moreover, in 13 cases (44.8) there is a section dedicated to University, in 12 (41.4\%) one dedicated to Culture and Society, regarding books and concerts, and 11 (38\%) dedicated to the more general News. Only 6 (20.7\%) magazines are in possession of an Opinions section, which includes students' experiences of university life and experiences of extra-university activities. While, 5 magazines (17.2\%) present a section devoted specifically to Warnings and $4(13.8 \%)$ to Opportunities for Students and Sport, only 2 (6.9\%) are interested in Relations with the Territory and $2(6.9 \%)$ in Relations with Businesses. Only 1 (3.4\%) magazine devotes a section to Weather and School; another one (3.44\%) does not explicitly state the content which is therefore generic .Generally, all contents are regularly upgraded: at least once a week.

The ease with which the Web can be used is ranked in 3 classes: low, medium and high .We found low usability in $8(27.6 \%)$ magazines, and medium in $21(72.4 \%)$. Editorial staff went from 1 to 5 people in $3(10.3 \%)$ cases; from 6 to 10 in $2(6.9 \%)$ cases; over 11 in $6(20.7 \%)$ cases. In $18(62.1 \%)$ cases, there was no information available regarding staff numbers. Only 1 magazine had advertising space.

As for the use of social media, we identified a direct link to Facebook in $24(82.7 \%)$ magazines, Twitter in 22 (75.9\%), YouTube in 18 (62\%), LinkedIn in 16 (55.2\%), Instagram in 12 (41.4\%), Google Plus in 10 (34.5\%). Moreover, we also identified a low percentage of other social media such as Flicker in 4 (13.8\%) magazines, iTunes in 2 (6.8\%), Vimeo and WhatsApp in 1 (3.4\%). The target user group was often declared, except in 1 case. In all the magazines, the content was aimed at students. There were also magazines directed at teachers in 28 $(96.5 \%)$ at researchers in $9(31 \%)$, at companies in $5(17.2 \%)$, at citizens in $3(10.3 \%)$ and at academic administration staff in $1(3.4 \%)$. Only in 1 case did we find a link to university apps or television channels although in 4 cases we did observe a link to the web-radio of the university in question. In 1 magazine a Google map was provided to identify the geographical location of the university in question; in another one we found a blog and in 4 cases, a newsletter.

\section{Web-radio and Improving Magazine in WayOut project}

Even if Italian uni versity web-radios and on-line magazines are so undervalued by the academic world, we found they had been used in a project, called WayOut, carried out from 2012 to 2015 at Suor Orsola Benincasa University of Naples, in Southern Italy. The project was funded to develop new services and was focused on enhancing an entrepreneurial mindset in students from different faculties, utilising web 2.0 tools within the UBC.

Our premise was to recognise the central role played by the internship experience in the learning process as we considered it an opportunity to shape new skills for students, in an attempt to expand traditional learning aa well as to renew cooperation between the different parties involved in a new way. Here, the student is the bearer of new knowledge not only for uni versity but also for a company or institution. This bridge between university and world of work can be strengthened and made more incisive and efficient thanks to web 2.0 tools. In this way, our path was built by means of university web-radios and on-line magazines.

The aim of this project was to create an engaging and interesting learning environment, in an informal, creative, stimulating way in order to encourage interaction between the different parties involved. At the same time, we aimed to shape individual students to be their own personal entrepreneur so as to be able to take full advantage of opportunities which arise in accordance with their aspirations and ambitions regarding future careers.

In order to achieve this, we designed a radio show, which was broadcast once a week for one hour, for the whole academic year. We held live interviews in the studio or on the telephone, with staff from government, companies 
(managers, CEOs, start-uppers, incubators, funders) as well as with students and teachers. Each show had one guest, one teacher, two students, and the interviewer of course. The issues discussed were geared to explore the business world, new products, new organizational methods, successful and failed start-ups, new funding, sustainability, innovation, up-coming events in the city or nationwide as well as comments about recently published articles. The studio atmosphere during these interviews was very relaxed and resulted in common interests between the different parties involved coming to light. In practically every interview, new friendships were forged and old ones rekindled. Audience numbers were high; about 500 listeners a day..

Many agreements for internships were planned during the project. We started with 912 agreements in 2011 but, by 2012 , this number was increasing year by year: in 2015 we had 1.321 agreements, confirmation of this positive trend (della Volpe \& Esposito, 2017). In the same period, we designed an on-line magazine, called' Improving Magazine', with its blog focused on the topic of internship which was considered a path to strengthen dialogue and collaboration between universities -, particularly students - industry and government. The home page was dedicated to the introduction of the parties involved and the aims of the magazine. This was followed by sections for news, companies, students, events, stories, suggestions, research and publications, and a list of contacts. naturally. In the news area, internships offered by companies or institutions were published. We previewed a list of partnerships. In the companies' section, we published the profiles of individual companies, based on our agreements with them. As well as a summary of the company's history, we inserted interviews by managers or by other managerial staff, internship offers and the requisites necessary to become a successful candidate. Moreover, there was an information box where students could express their opinions about the internships. For example, they discussed the duration of the internship, the choice of going abroad on an internship, the quality and difficulties of an internship, the desire to continue the internship experience, as well as the possibility of being paid while undertaking an internship.

In the students' section, companies and institutions could find students' profiles, their academic and personal histories and work experience in the business world after their graduation. .In the events section we listed meetings, workshops, conferences promoted by associations, private citizens and the business or university world. We collected reports on them, descriptions, press releases, pictures and videos. In the section, "Tell us your story" students could discuss their experiences, their feelings, the skills they had improved, and their first impact with the work of world. There was also a section for suggestions deemed useful to deal with organizations, to write a $\mathrm{CV}$ or a presentation letter and to do a good job interview. Finally, in the research and publication section, we published scientific papers, reports, surveys about UBC and higher education. Every section included comments under the posts, in order to generate conversations and interaction among readers..

Then in 2015, students who had participated in a Communication Lab, were involved in getting the magazine ready for publication. They made new videos, took pictures, did interviews and wrote summaries of scientific papers regarding internships or other related issues, such as start-ups, innovation, learning and. entrepreneurship .At each step of building implementing or improving the magazine, the students had a central role: they were constantly directed by a teacher but worked autonomously in a team.

A similar strategy was adopted on the web-radio: students filled all the positions, such as editor, speaker, broadcast technicians etc.: before starting, they attended a 20 hours Lab and then they were selected for their internship at the uni versity web-radio, they were answerable to the artistic director, the only staff member who was not a student. The magazine was directly connected to web-radio activities. Every 'WayOut' radio show became a podcast, which could be downloaded from the magazine and therefore could be listened to on different devices thus increasing user numbers also regarding similar topics by taking advantage of the network, which would shortly be available.

\section{Conclusions}

We have ascertained that relationships between the different parties involved in EU building are encouraged through the use of web 2.0 tools, such as university web-radios and on-line magazines. . These tools are a way to strengthen partnerships, as well as a way to encourage the different parties to be actively involved in the process; they also stimulate creativity, passion and sharing. We found that active involvement accelerated the learning process for universities, industries, government and citizens alike. These tools helped us to build a network where the participants all have a common aim, be it temporary or permanent. Within the network, new participants can join or others can leave: it is a very dynamic context.

Traditional activities are renewed and redesigned by new tools. As we have verified, internships are beneficial to both the world of work and the world of academia. They help, produce highly qualified, motivated students by eliminating the barriers which exist between academia and business. Their different languages different scientific 
and practical ways of working and studying, have the opportunity to find common ground where they can compare their two different worlds. They also present the opportunity to develop new knowledge.

A lack of data in this field meant the only result we could verify was that the number of internships is rising. Therefore, we suggest that the next Social Network Analysis, or other selected analysis, could be used to provide solid examples to observe the network in question or, alternatively, to identify which students' skills were improved.

Traditional teaching methods should be redesigned and renewed by consulting all those involved in the learning process: students, teachers, institutions, companies etc. in order to create a network whose aim is to exchange and transfer knowledge. The criteria used to choose a distance learning course program, should also be applied to building the right network to reach predetermined goals. In both cases, we have a classroom - real or virtual- and it is only when we step outside the usual learning environment, that we can increase learning opportunities, by stimulating and motivating learners in a new way. Stepping out of the traditional classroom environment results in an open mind regarding the world of work, especially in the field of Business Education. Finally, it should be underlined that all those who have been involved in the network have gained professionally from the experience,

Finally, we have not to forget that a good, positive reputation occur to all players involved in the network considered.

\section{References}

Bennett, S., Bishop, A., Barney Dalgarno, B., Waycott, J., \& Kennedy, G. (2012). Implementing Web 2.0 technologies in Higher Education: A collective case study. Computers \& Education, 59, 524-534. https://doi.org/10.1016/j.compedu.2011.12.022

Berners-Lee, T. (1997). The power of the Web is in its universality. Access by everyone regardless of disability is an essential a spect, Web Accessibility Initiative, W3C, WASHINGTON DC, USA.

Bower, M. (2016). Deriving a typology of Web 2.0 learning technologies. British Journal of Educational Technology, 47(4), 763-777. https://doi.org/10.1111/bjet.12344

Boyd, D. (2007). The significance of social software. In T. N. B. J. Schmidt (Ed.), BlogTalks reloaded: social software research \& cases, (pp. 15-30). Norderstedt: Books on Demand.

Carayannis, E. G., \& Campbell, D. F. (2009). 'Mode 3'and'Quadruple Helix': toward a 21st century fractal innovation ecosystem. International journal of technology management, 46(3-4), 201-234. https://doi.org/10.1504/IJTM.2009.023374

Carayannis, E. G., \& Campbell, D. F. J. (2010). Triple Helix, Quadruple Helix and Quintuple Helix and how do knowledge, innovation and the environment relate to each other? A proposed framework for a trans-disciplinary analysis of sustainable development and social ecology. International Journal of Social Ecology and Sustainable Development, 1(1), 41-69. https://doi.org/10.4018/jsesd.2010010105

Carayannis, E. G., Barth, T. D., \&Campbell, D. F. J. (2012). The Quintuple Helix innovation model: global warming as a challenge and driver for innovation, Journal of Innovation and Entrepreneurship, 1(1), 2. https://doi.org/10.1186/2192-5372-1-2

Conde, M. Á., García-Peñalvo, F. J., Rodríguez-Conde, M. J., Alier, M., Casany, M. J., \& Piguillem, J. (2014) An evolving Learning Management System for new educational environments using 2.0 tools. Interactive Learning Environments, 22(2), 188-204. https://doi.org/10.1080/10494820.2012.745433

De Pablos Pons, J. (2007). El cambio metodológico en el Espacio Europeo de Educación Superior y el papel de las tecnologías de la información y la comunicación. RIED. Revista Iberoamericana de Educación a Distancia, 10(2), 15-44.

Della Volpe, M. (2013). Imprese tra web 2.0 e big data, Milano: Cedam.

Della Volpe, M., \& Esposito, F. (2017, June 9-11). Universities web-radio: a web-based tool to improve industries, institutions and academic interaction, Paper presented at the UIIN Conference 2017, Dublin, Ireland.

Downes, S. (2005). E-learning 2.0. E-learn magazine, 10, 1.

Etzkowitz, H. (1983). Entrepreneurial Scientists and Entrepreneurial Universities in American Academic Science. Minerva, 21(2-3), 198-233. https://doi.org/10.1007/BF01097964

Etzkowitz, H. (2002). The triple helix of university-industry-government: implications for policy and evaluation . 
Swedish Institute for Studies in Education and Research.

GfK, E., \& Ipsos (2015, October). Come afferrare Proteo. La prima Ricerca di Base sulla Radio. Retrieved February 7, 2017 (Available from http://www.system24.ilsole24ore.com/it//wp-content/uploads/sites/2/2015/10/Cartella-Stampa_28-ottobre-b is.pdf)

Jenkins, H. (2006). Convergence culture: Where old and new media collide. New York: NYU Press.

Khan, S. (2012). The one world Schoolhouse. Education re-imagined.New York: Twelve-Hachette Book Group.

Kulakli, A., \& Mahony, S. (2014). Knowledge creation and sharing with Web 2.0 tools for teaching and learning roles in so-called University 2.0, 10th International Strategic Management Conference, 10th International Strategic Management Conference. Procedia, Social and Behavioral Sciences, 150, 648-657. https://doi.org/10.1016/j.sbspro.2014.09.084

Levine, A., \& Sun, J. C. (2002). Barriers to distance education. Distributed Education: Challenges, Choices, and a New Environment, American Council on Education Center for Policy Analysis ,EDUCAUSE, 6,1-28. Available from http://www.acenet.edu/news-room/Documents/Barriers-to-Distance-Education-2003.pdf

Narayanan, V. K., Olk, P. M., \& Fukami, C. V. (2010). Determinants of Internship Effectiveness: An Exploratory Model. Academy of Management Learning \& Education, 9(1), 61-80. https://doi.org/10.5465/AMLE.2010.48661191

O'Reilly, T. (2007). What is Web 2.0: design patterns and business models for the next generation of software. Communications and Strategies, 65(1), 17-37.

Roper, S. (2013). Entrepreneurship. A global perspective. London \& New York: Routledge.

Tapscott, D., \& Williams, A. D. (2010). Innovating the 21 st-century university: It's time! EDUCAUSE review, 45(1), 16-29.

Wissema, J. G. (2009). Towards the third generation university: managing the university in transition. Cheltenham: Edward Elgar Publishing. https://doi.org/10.4337/9781848446182

\section{Copyrights}

Copyright for this article is retained by the author(s), with first publication rights granted to the journal.

This is an open-access article distributed under the terms and conditions of the Creative Commons Attribution license (http://creativecommons.org/licenses/by/4.0/). 